OPEN ACCESS

Edited by:

Keng-Te Lin,

Swinburne University of Technology,

Australia

Reviewed by:

Jialiang Wang,

University of Wisconsin-Madison,

United States

Xifeng Ding,

Nanjing University of Science and

Technology, China

Kongfa Chen,

Fuzhou University, China

*Correspondence:

Guang-Hong Ao

aghoptics@163.com

Zhi-Hong Wang

wangzhihong@hit.edu.cn

Specialty section: This article was submitted to

Energy Materials,

a section of the journal

Frontiers in Materials

Received: 17 June 2021

Accepted: 27 August 2021

Published: 08 October 2021

Citation:

Ao G-H, Zhao P-Z, Peng Z-G, Wang S, Guo $Y$-S, Chen $C-T$ and Wang $Z-H$ (2021) Construction of Hierarchical

Porous Architecture on Ni Foam for

Efficient Oxygen Evolution

Reaction Electrode.

Front. Mater. 8:726270.

doi: 10.3389/fmats.2021.726270

\section{Construction of Hierarchical Porous Architecture on Ni Foam for Efficient Oxygen Evolution Reaction Electrode}

\author{
Guang-Hong Ao ${ }^{1 *}$, Pei-Zhi Zhao ${ }^{1}$, Zhi-Gang Peng ${ }^{1}$, Shuo Wang ${ }^{2}$, Ying-Shuang Guo ${ }^{2}$, \\ Chun-Tian Chen ${ }^{2}$ and Zhi-Hong Wang ${ }^{2 *}$
}

${ }^{1}$ School of Science, Harbin University of Science and Technology, Harbin, China, ${ }^{2}$ School of Physics, Harbin Institute of Technology, Harbin, China

Nickel foam (NF) with a three-dimensional porous structure plays an important role in a wide variety of applications such as energy storage and conversion, catalysis, and sensor due to its high porosity, low density, and excellent conductivity. However, the main drawback of NF is that its ligaments are very smooth, and thus the surface area is relatively low. In this work, we propose a novel strategy, oxidization and reduction process, in situ to construct micron/nano pores on the ligaments of commercial NF to fabricate a typical hierarchical porous architecture. This process is simple and green, avoiding the use of sacrificial materials. Furthermore, $\mathrm{MnO}_{2}$ is coated on the micron/nano-porous $\mathrm{Ni}$ foam (MPNF) to construct an oxygen evolution reaction (OER) electrode through pulse electrodeposition. The designed $\mathrm{MPNF}-\mathrm{MnO}_{2}$ electrode presents enhanced OER electrocatalysis activity with a low overpotential of $363.5 \mathrm{mV}$ at the current density of $10 \mathrm{~mA} \mathrm{~cm}^{-2}$ in an alkaline solution, which is $66.4 \mathrm{mV}$ lower than that of the $\mathrm{NF}-\mathrm{MnO}_{2}$ electrode in the same operating conditions. Furthermore, the porous and wrinkled structures of the MPNF also improve the mechanical integrity of the electrode, resulting in super-long stability.

Keywords: oxidation-reduction, micron/nano-structure, oxygen evolution reaction, current collector, nickel foam

\section{INTRODUCTION}

Nickel foam (NF) is a three-dimensional (3D) porous metal composed of pores and ligament skeleton with the advantages of high porosity, good conductivity, and mechanical performance, which has very important applications in many fields such as energy storage and conversion, catalysis, and sensing (Yuan et al., 2012; Zhou et al., 2013; Huang et al., 2015; Tong et al., 2019; Zeng et al., 2020). With the rapid development of the new energy technology, NF was demonstrated to be promising excellent electrodes/catalysts or their supports, which has attracted considerable attention. However, as the commercial NF was prepared for diverse applications, its natural architecture could not always meet the demand of the electrochemical electrode/support. For example, the pore diameter of NF was in the range of hundreds of microns and the porosity could be as high as $90 \%$, whereas the proportion of the ligament was relatively small and its diameter was $\sim 50 \mu \mathrm{m}$. Taking electrochemical electrode in solution as an example, the large pore structure in NF was indeed conducive to liquid infiltration and ion transmission (Xu et al., 2015). However, the lower active surface of ligaments became a major obstacle, limiting the electrochemical performance. Furthermore, when NF was applied as an electrode/catalyst support, the surface of the ligament was smooth, which was not beneficial for the adhesion of active materials on its surface. The shedding 
of active materials on NF support was indeed a serious issue for the long-term stability of the electrode/catalyst (Yu et al., 2014).

To overcome these problems, acid-base corrosion and dealloying have been developed for the treatment of NF. However, it is a certain technical challenge to carry out the elaborate process on these ligaments with such small diameters to increase their coarseness uniformly. Yu et al. (Yu et al., 2014) developed a porous $\mathrm{Ni@NiO} \mathrm{core-shell} \mathrm{electrode}$ obtained by activated commercial $\mathrm{Ni}$ foam (NF) in a $3 \mathrm{M} \mathrm{HCl}$ solution at $90{ }^{\circ} \mathrm{C}$. The asymmetric supercapacitor based on the electrode exhibited an ultrahigh areal capacitance and super-long cycling stability. Xu Guorong et al. (Xu et al., 2015) created a porous structure with $1-15 \mu \mathrm{m}$ cracks on the ligaments of NF by the alloying and dealloying approach. In this process, nickel-zinc alloy was first prepared by electrochemical deposition on the ligament of NF, and then the higher active $\mathrm{Zn}$ was removed by electrochemical dealloying. The porous $\mathrm{Ni}$ foam could be used as an efficient supercapacitor substrate to increase the loading capacity for the $\mathrm{MnO}_{2}$ electrode. However, for these existing treatments for NF, a strong acid was often needed in the corrosion and dealloying treatment, which is harmful to the environment. Furthermore, the dealloying process requires time-consuming preparation of an alloy precursor and subsequent removal of active metal, which is complex and a waste of resource. Therefore, it is highly desirable to develop a simple, green, and efficient technology for treatment of NF.

This work reports a novel oxidation-reduction method for in situ micron/nano-porous treatment of commercial NF. The formation of pore structures on NF can be attributed to the volume expansion and shrink during the oxidation-reduction process, as well as the diffusion and spontaneous reconstruction of nickel atoms. This process is simple and green, avoiding the use of sacrificial materials. Furthermore, as a representative application, $\mathrm{MnO}_{2}$ is coated on an MPNF to construct an OER electrode through pulse electrodeposition. The designed MPNF- $\mathrm{MnO}_{2}$ electrode presents excellent OER electrocatalysis activity.

\section{EXPERIMENTAL}

\section{Fabrication of MPNF}

The purchased commercial NF (99.9\%, LZY Battery Sales Department, China) was placed in a furnace and oxidized at $850^{\circ} \mathrm{C}$ for $36 \mathrm{~h}$ in atmospheric air. Then, oxidized NF was placed in a tube furnace and reduced at $650^{\circ} \mathrm{C}$ for $10 \mathrm{~min}$ under a hydrogen atmosphere. The MPNF samples were fabricated through simple oxidation and subsequent reduction treatment.

\section{Preparation of the Composite Electrode}

The prepared MPNF and NF were cleaned with acetone, anhydrous ethanol, and deionized water. $\mathrm{MnO}_{2}$ was coated on the two kinds of supports through pulse electrodeposition in the three-electrode system proposed by Li et al. (Li et al., 2016). Ag/ $\mathrm{AgCl}$ and platinum pallets were employed as reference and counter electrodes, respectively. $0.1 \mathrm{~mol} \mathrm{~L}^{-1}$ of $\mathrm{KMnO}_{4}$ was selected as an electrolyte. Each pulse electrodeposition cycle consisted of on-time of $1 \mathrm{~s}$ at $-0.15 \mathrm{~V}$ and off-time of $10 \mathrm{~s}$ at $0.65 \mathrm{~V}$. The mass loading was tuned by the change of electrodeposition cycles (15, 25, and 35 cycles).

\section{Material Characterization and Electrochemical Measurement}

The microstructures of $\mathrm{MPNF} / \mathrm{NF}-\mathrm{MnO}_{2}$ composite electrode were observed by scanning electron microscope (SEM, JEOL$2100 \mathrm{~F})$. The phases were characterized by X-ray diffraction (RIGAKU D/max2200, Japan) and Raman spectroscopy (Raman, nanobase, $532 \mathrm{~nm}$ laser).

Electrochemical tests were carried out in $1 \mathrm{~mol} \mathrm{~L}^{-1} \mathrm{KOH}$ electrolyte at $25^{\circ} \mathrm{C}$ by $\mathrm{CHI} 660$ e electrochemical workstation (Shanghai ch instruments, China). $\mathrm{Hg} / \mathrm{HgO}$ and $\mathrm{Pt}$ were used as reference and counter electrodes, respectively. EIS (electrochemical impedance spectroscopy) was tested at $1.62 \mathrm{~V}$ potential (vs RHE) and $5 \mathrm{mV}$ AC voltage. The frequency range of the test was from high frequency $10^{5} \mathrm{~Hz}$ to low frequency $10^{-2} \mathrm{~Hz}$. The long-term stability of the composite electrodes was evaluated by chronopotentiometry.

\section{RESULTS AND DISCUSSION}

\section{Fabrication and Characterization of MPNF}

Figures 1A-C shows the construction process of micron/nanoporous structure on the ligament of NF by an oxidation-reduction method. As seen in Figure 1A, the commercial NF exhibited a typical metallic luster. The diameter of the pores was in the range of hundreds of micrometers, and the diameter of the ligaments was in the range of tens of micrometers. As mentioned above, such "larger pores and smaller ligament" structures reduced the effective active area of the NF to a certain extent. Figures 1D and $\mathrm{G}$ show the SEM images of fresh NF. The crystalline grain in the ligaments was obvious and continuous, forming a smooth surface without pore and wrinkle structures. Figure $\mathbf{1 B}$ is an electronic image of NF after oxidation. The color of NF changed from metallic luster to dark green which indicates the formation of $\mathrm{NiO}$. As shown in Figure $\mathbf{1 E}$ and $\mathbf{H}$, a number of particles grew out of the surface of the $\mathrm{Ni}$ foam, suggesting the formation of $\mathrm{NiO}$ grains. These grains presented a typical "ridged" appearance, which was consistent with the microstructures of $\mathrm{Ni} / \mathrm{NiO}$ after oxidation at $900^{\circ} \mathrm{C}$ (Haugsrud, 2003). The formation of $\mathrm{NiO}$ on NF was further confirmed by the XRD patterns (Figure 1K) and Raman spectra (Figure 1M).

From Figure 1C, after the reduction treatment, the color of NF almost recovered its metallic luster. The reflectivity seems to decrease slightly owing to the construction of micron/nano-pore structures. The SEM images in Figures 1F,I show that a large number of micron/nano-pores and wrinkles appeared on the surface of NF after the oxidation-reduction treatment. The amount of pores reached $\sim 45$ per $100 \mu \mathrm{m}^{2}$ with an average of $\sim 214 \mathrm{~nm}$ (Figure 1J). The average pore size of the MPNF was smaller than that of cracks $(\sim 15 \mu \mathrm{m})$ prepared by dealloying (Xu et al., 2015), which is a more beneficial and effective support for 
A
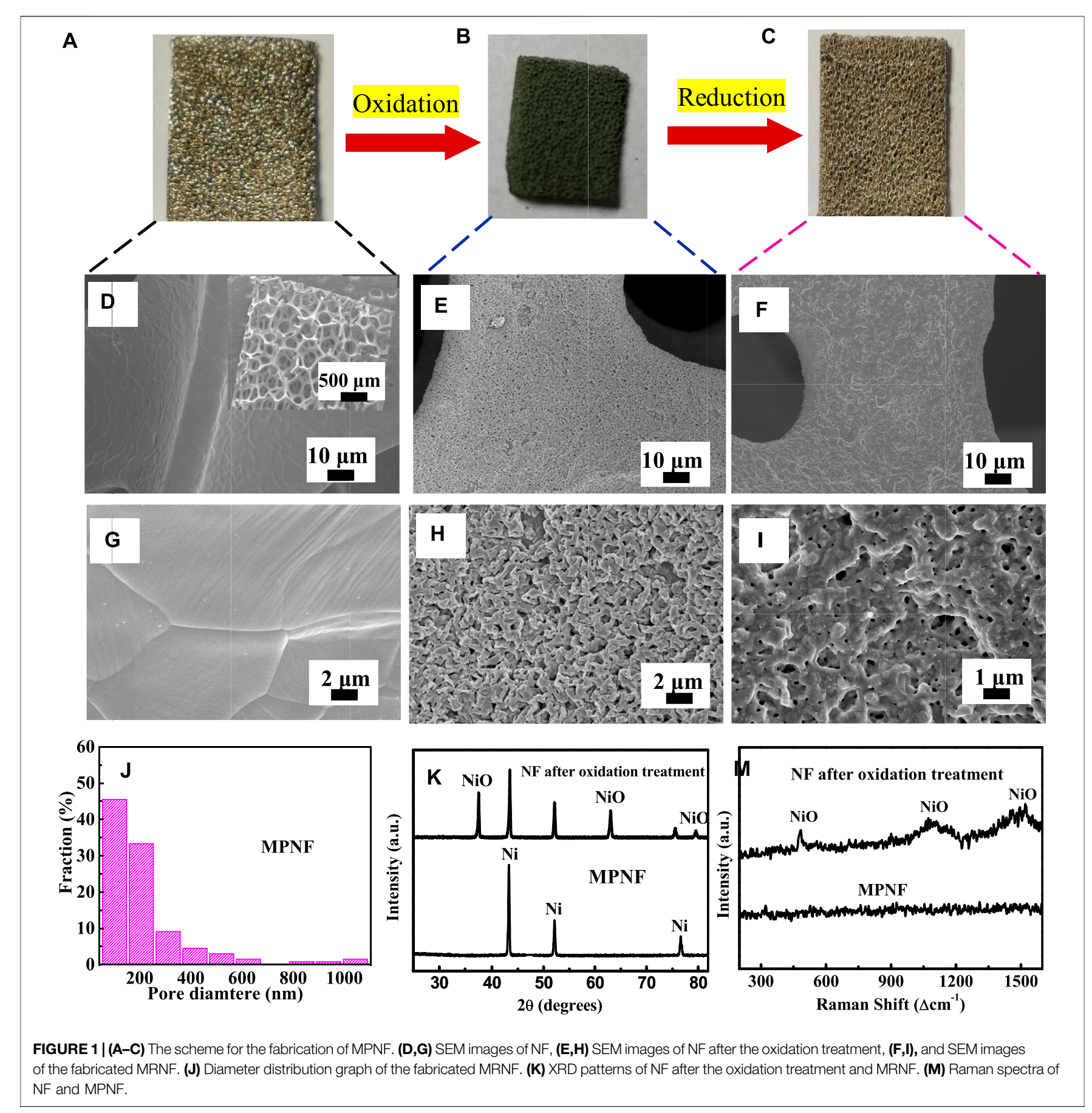

B

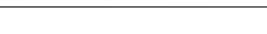

nanometer catalyst materials. The formation of the micron/nanostructure is mainly due to the oxidation-reduction process. At the first stage of the oxidation process, a dense oxide layer was formed on the surface of NF. With further progress of oxidation, nickel atoms needed to diffuse outward through the oxide layer, while oxygen atoms also needed to diffuse inward through the oxide layer. However, the diffusion rate of nickel atoms in the oxide layer was much higher than that of nickel diffusion in the oxide layer. For example, at $1400^{\circ} \mathrm{C}$, the diffusion rate of $\mathrm{Ni}^{2+}$ was 6 orders of magnitude higher than that of $\mathrm{O}^{2-}$ (Faes et al., 2012).
Therefore, simultaneous diffusion of the two kinds of atoms will lead to the formation of internal defects (pore structures) in the inside of the ligament, which can be considered as a Kendall effect (Galinski et al., 2011). Afterward, as the oxidized NF was reduced in the $\mathrm{H}_{2}$ atmosphere, the oxygen atoms were taken away and quick volume shrinkage took place. The volume shrinkage for the reduction of $\mathrm{NiO}$ was as high as $41 \%$. Rapid reduction and volume shrinkage promoted the formation of porous structure on the surface of NF, resulting in the exposure of porous structure that was originally covered under the oxide layer (Nakamura 

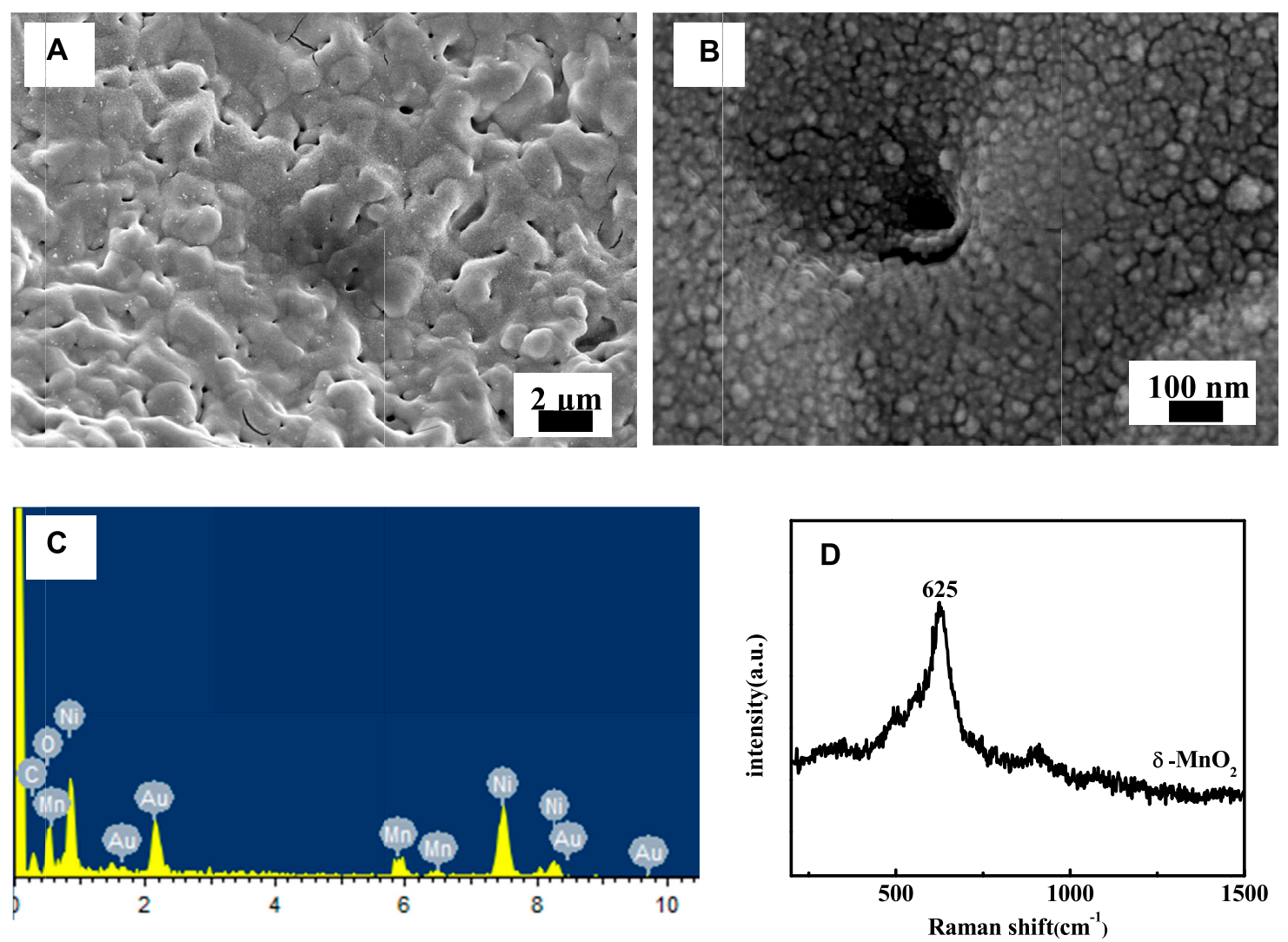

FIGURE 2 | (A) Low- and (B) high-magnification SEM images of MPNF-MnO $\mathrm{M}_{2}$ electrode. (C,B) are the EDX analysis and Raman spectra of the MPNF-MnO 2 electrode, respectively.

et al., 2008; Wang et al., 2017). In addition, the wrinkled structure observed on MPNF was mainly due to the surface reconstruction formed by the spontaneous migration of nickel atoms in the process of long-time oxidation and high-temperature thermal etching (Meulenberg et al., 2001). These wrinkle structures also significantly increased the roughness of the nickel ligament surface, which is conducive to improve the contact area between MPNF and active materials. In this approach, through this simple metal oxide-metal treatment, commercial NF was directly transformed to MPNF with hierarchical porous architecture. The large pores in the skeleton of MPNF could ensure the fast ion transport in the solution and the formed micron/nano pores and wrinkle structures in the ligaments of MPNF inevitably expands the effective area. The MPNF could be used as a promising electrode/electrode support.

XRD in Figure $1 \mathbf{K}$ exhibited that the formed MPNF was composed of pure Ni without any impurities. This was confirmed by the more sensitive Raman spectra in Figure 1M. The Raman spectrum of MPNF was a typical metal spectrum without any peaks, indicating that there was no detectable $\mathrm{NiO}$ after the $\mathrm{H}_{2}$ reduction treatment under this experimental condition. In contrast, when acid etching was used to form a porous structure, oxide particles will be formed ( $\mathrm{Yu}$ et al., 2014). While, the dealloying process could leave residual active metal components in the formed porous structure (Xu et al., 2015).
Compared with the traditional acid-base corrosion and dealloying approaches, this approach avoids the involution of impurities in principle, which can prepare pure micron/nanoporous metals without the participation of acid-base solutions. Therefore, it is a green and large-scale approach.

\section{Characterization of Phase and Microstructures of MPNF- $\mathrm{MnO}_{2}$ Composite Electrodes}

Figures 2A,B are the microstructures of MPNF- $\mathrm{MnO}_{2}$ composite electrodes prepared through pulse electrodeposition of $\mathrm{MnO}_{2}$ for 25 cycles. The electrodeposited $\mathrm{MnO}_{2}$ film was uniformly covered on the surfaces of MPNF, which makes the micron/nano-porous structure of the surface fuzzy. Furthermore, many clusters of $\mathrm{MnO}_{2}$ particles have been plated into the micron/nano-porous structure to form a unique contact interface between MPNF and $\mathrm{MnO}_{2}$. Some researchers reported that the active materials embedded in the micro/nano-porous support can expand the contact interface between support and active materials, resulting in the improvement of the electrochemical performance stability of the electrodes (Lang et al., 2011; Meng and Ding, 2011; Wang et al., 2017). The results of EDX (Figure 2C) further confirmed that Mn oxides were formed on the surface of MPNF. The typical peak of $625 \mathrm{~cm}^{-1}$ (Figure 2D) in the Raman spectrum of the 

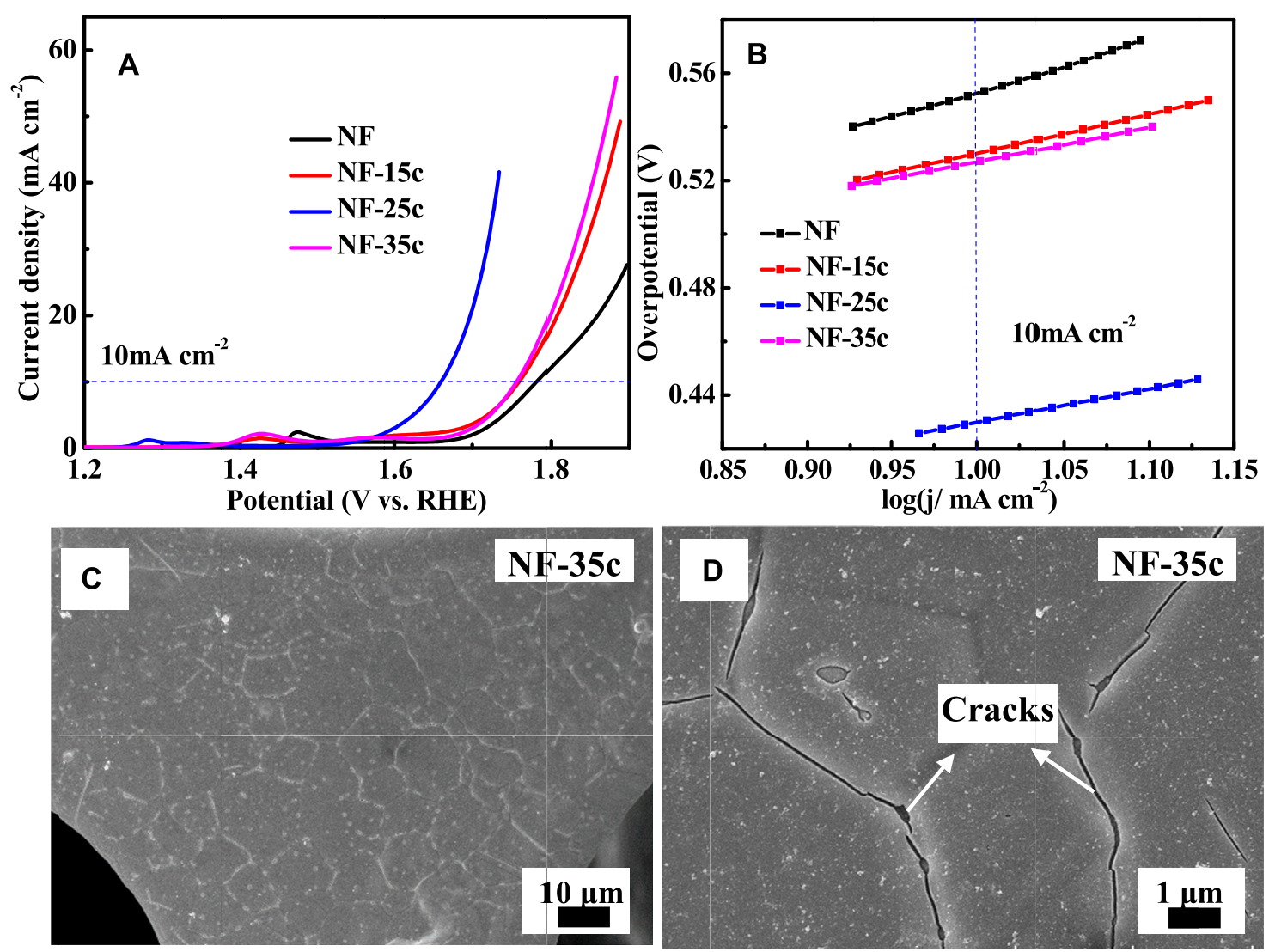

FIGURE 3 | OER measurement curves of the electrode with different cycles of electrodeposition (A) LSV curves and (B) Tafel slopes. The (C) low and (D) high magnification SEM images of NF-MnO 2 electrode with pulse electrodeposition for 35 cycles.

$\mathrm{MnO}_{2}$ film was consistent with the report in the literature (Julien et al., 2002). It has been reported that $\delta$ type $\mathrm{MnO}_{2}$ was formed through the pulse electrodeposition.

\section{Electrochemical Performance}

It was reported the loading mass of active material was an important parameter on the electrochemical performance of the composite electrodes ( $\mathrm{Li}$ et al., 2016). In this study, to determine the effects of pulse electrodeposition cycles on the OER electrocatalytic performance of the composite electrodes, the number of electrodeposition cycles ( $15-35$ cycles) was tuned. In Figure 3 the electrode with 25 cycles shows the minimum overpotential and the minimum Tafel slope at a current density of $10 \mathrm{~mA} \mathrm{~cm}^{-2}$, demonstrating the superior electrochemical activity. This was understandable because as the number of electrodeposition cycles was less, the electrochemical performance was poor mainly owing to the lack of active materials. Meanwhile, the electrochemical performance of the composite electrode could not increase monotonously with the continuous increase in electrodeposition cycles considering that obvious cracks were observed in the thick $\mathrm{MnO}_{2}$ layer as the pulse electrodeposition cycle was increased to 35 (Figures 3C,D). In addition, with a continuous increase in thickness of $\mathrm{MnO}_{2}$, the outer layer does not participate in the catalytic reaction fully due to its poor electrical conductivity (Huang et al., 2015). In general, there was an appropriate loading mass for each electrode support. Therefore, in this study, we considered the suitable cycle of electrodeposition to be 25 , and thus the composite electrodes in the following were prepared under the same electrodeposition conditions.

Considering that Ni-based metals could be used as selfsupporting oxygen evolution electrodes, the OER electrocatalytic properties of NF, MPNF, NF, $\mathrm{MnO}_{2}$, and MPNF- $\mathrm{MnO}_{2}$ were characterized through a three-electrode system (Figure 4). From the LSV curves of NF and MPNF in Figure $\mathbf{4 A}$, a peak in the potential range of $1.327-1.328 \mathrm{~V}$ was observed, which corresponded to the oxidation peak of $\mathrm{Ni}$ (II)/Ni (III) (Yu et al., 2016). There was a more obvious peak in the potential range of $1.28-1.29 \mathrm{~V}$ for the composite electrodes of $\mathrm{NF}-\mathrm{MnO}_{2}$ and $\mathrm{MPNF}-\mathrm{MnO}_{2}$, which was ascribed to the oxidation peak of Mn (II)/Mn (III) (Devadoss et al., 2003). MPNF and MPNF- $\mathrm{MnO}_{2}$ electrodes exhibited higher electrocatalytic activities than those of the corresponding reference electrodes ( $\mathrm{NF}$ and $\mathrm{NF}-\mathrm{MnO}_{2}$ ). The overpotential of MPNF- $\mathrm{MnO}_{2}$ at $10 \mathrm{~mA} \mathrm{~cm}^{-2}$ was $363.5 \mathrm{mV}$, which was lower than that of MPNF $(370.6 \mathrm{mV}), \mathrm{NF}-\mathrm{MnO}_{2}(429.9 \mathrm{mV})$, and NF $(444 \mathrm{mV})$. Furthermore, the overpotential was lower than those of most reported electrodes with manganese oxide as the active 

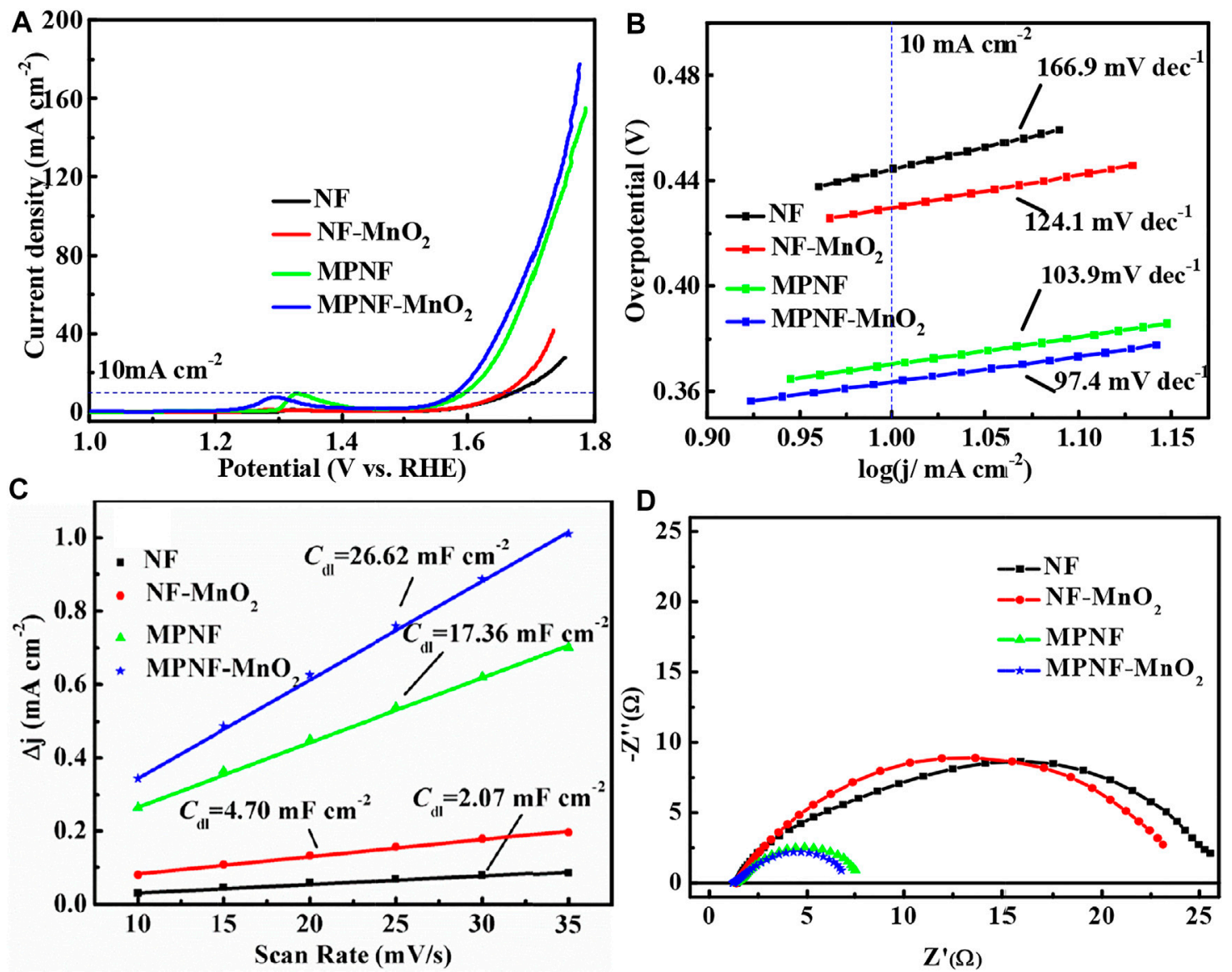

FIGURE 4 | OER curves of NF, MPNF, NF-MnO 2 , and MPNF-MnO 2 . (A) LSV at $5 \mathrm{mV} / \mathrm{s}$ of scanning rate, (B) Tafel slope linear, (C) $C_{d l}$ linear fit by C-V curve, and (D) EIS curves at $1.62 \mathrm{~V}$ (VS RHE).

TABLE 1 | Comparisons of OER activities of electrodes based on $\mathrm{MnO}_{2}$.

Active materials

$\delta-\mathrm{MnO}_{2}$

$\mathrm{MnO}_{2}$

$\beta-\mathrm{MnO}_{2}$

$\mathrm{Ni}^{2+} / \mathrm{MnO}_{2}$

$\mathrm{MnNixOx}$

$\delta-\mathrm{MnO}_{2}$

$\mathrm{MnO}_{2}$

$\mathrm{Co}^{2+} / \mathrm{MnO}_{2}$

$\mathrm{a}-\mathrm{MnO}_{2}$

$\mathrm{MnO}_{2}$ with various structures

Ultrathin $\delta-\mathrm{MnO}_{2}$
Electrolyte

$1 \mathrm{M} \mathrm{KOH}$

$1 \mathrm{M} \mathrm{NaOH}$

$1 \mathrm{M} \mathrm{NaOH}$

$1 \mathrm{M} \mathrm{KOH}$

$0.1 \mathrm{M} \mathrm{KOH}$

$0.1 \mathrm{M} \mathrm{KPi}$

$1 \mathrm{M} \mathrm{KOH}$

$1 \mathrm{M} \mathrm{KOH}$

$1 \mathrm{M} \mathrm{KOH}$

$1 \mathrm{M} \mathrm{KOH}$

$1 \mathrm{M} \mathrm{KOH}$
Supports

\section{MPNF}

Glassy Carbon

Carbon Paper

Glassy Carbon

Glassy Carbon

Glassy Carbon

Carbon fiber paper

Glassy Carbon

Ni Foam

Pyrolytic Graphite Carbon

Ni Foam
Overpotential (mV)

363.5

500

450

400

430

441

467

360

357

490-740

320

\section{Current density $\left(\mathrm{mA} \mathrm{cm}{ }^{-2}\right.$ )}

10
$\mathrm{~N} / \mathrm{A}$
10
10
10
10
20
10
10
5
10

References

This work

Jung et al. (2016)

Kim et al. (2016)

Thenuwara et al. (2016a)

Ledendecker et al. (2015)

Bergmann et al. (2013)

Ye et al. (2017)

Thenuwara et al. (2016b)

Tian et al. (2020)

Meng et al. (2014)

Zhao et al. (2017) material (Table 1). The Tafel slope of the MPNF- $\mathrm{MnO}_{2}$ electrode $\left(97.4 \mathrm{mV} \mathrm{dec}^{-1}\right)$ is lower than that of MPNF $\left(103.9 \mathrm{mV} \mathrm{dec}{ }^{-1}\right)$, $\mathrm{NF}_{-\mathrm{MnO}_{2}} \quad\left(124.1 \mathrm{mV} \mathrm{dec}^{-1}\right)$, and $\mathrm{NF} \quad\left(166.9 \mathrm{mV} \mathrm{dec}^{-1}\right)$ (Figure 4B), showing that the porous substrate obviously accelerates the dynamic process of the composite electrode.

To further investigate the enhancement mechanism of micron/nano-porous and wrinkle structures on MPNF for electrocatalytic activity toward OER, the electrochemically active areas (ECSA) of the four electrodes were extracted from $\mathrm{CV}$ curves (Figure 4C). The electric double-layer capacitance $\left(C_{\mathrm{dl}}\right)$ of $\mathrm{MPNF}-\mathrm{MnO}_{2}$ and MPNF were 26.62 and $17.36 \mathrm{mF}$, respectively, which are much higher than those of $\mathrm{NF}-\mathrm{MnO}_{2}$ $(4.70 \mathrm{mF})$ and NF $(2.07 \mathrm{mF})$. The double capacitance of MPNF is $\sim 8$ times higher than that of NF, which indicates that the specific 


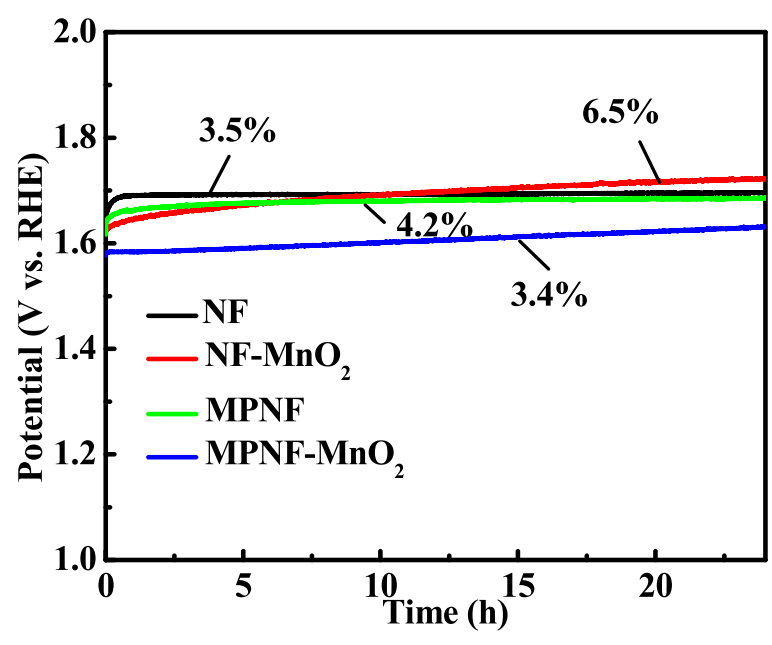

FIGURE 5 | The long-term stability of the MPNF- $\mathrm{MnO}_{2}$ and $\mathrm{NF}-\mathrm{MnO}_{2}$ electrodes at a constant current density of $10 \mathrm{~mA} \mathrm{~cm}^{-2}$ for $24 \mathrm{~h}$.

surface area of NF could be greatly expanded by the formation of a micron/nano porous and wrinkle structures. Furthermore, the deposition of nano- $\mathrm{MnO}_{2}$ materials could increase the specific surface area of the supports. Considering these profiles of overpotential, Tafel slope, and $C_{\mathrm{dl}}$ of the electrodes, it can be concluded that the porous treatment of NF can significantly improve the OER electrocatalytic activity of the composite electrode. The enhancement of the performance was mainly due to the typical hierarchical porous architecture of MPNF. Larger pores in the skeleton of MPNF ensure the fast conduction of solution ions on the surface of the electrode, and the created micron/nano-porous structure on the ligament greatly increases the contact area between the MPNF and $\mathrm{MnO}_{2}$, reducing the electrochemical reaction resistance. This can be confirmed by the impedance spectrum of the electrode at a voltage of $1.62 \mathrm{~V}$ (Figure 4D). The charge transfer resistance $\left(R_{\mathrm{ct}}\right)$ of the MPNF- $\mathrm{MnO}_{2}$ electrode was $5.5 \Omega$, which was much lower than that of the $\mathrm{NF}-\mathrm{MnO}_{2}$ electrode $(21.7 \Omega)$.

Long-term stability is another key criterion to evaluate the catalytic performance of OER electrodes. The long-term stability of four electrodes at $10 \mathrm{~mA} \mathrm{~cm}^{-2}$ was investigated (Figure 5). It can be seen from the stability test curve that the overpotential of the MPNF- $\mathrm{MnO}_{2}$ electrode increased by $54 \mathrm{mV}$ within $24 \mathrm{~h}$. The increased rate of the overpotential of MPNF- $\mathrm{MnO}_{2}$ composite electrode was almost the same as that of $\mathrm{Ni}$ substrate. However, the increase in the overpotential of $\mathrm{NF}-\mathrm{MnO}_{2}$ composite electrode was as larger as $105 \mathrm{mV}$. The enhancement of the stability mainly depended on the added

\section{REFERENCES}

Bergmann, A., Zaharieva, I., Dau, H., and Strasser, P. (2013). Electrochemical Water Splitting by Layered and 3D Cross-Linked Manganese Oxides: Correlating Structural Motifs and Catalytic Activity. Energy Environ. Sci. 6 (9), 2745-2755. doi:10.1039/c3ee41194j micron/nano porous and wrinkle structure, increasing the contact area between the $\mathrm{Ni}$ support and $\mathrm{MnO}_{2}$ (Figure 2, 3). This could enhance the binding force between the active material $\mathrm{MnO}_{2}$ and the $\mathrm{Ni}$ collector to a certain extent, reducing the shedding of the deposited $\mathrm{MnO}_{2}$ from the $\mathrm{Ni}$ collector and improving the mechanical integrity of the electrode ( $\mathrm{Xu}$ et al., 2015; Wang et al., 2017).

\section{CONCLUSIONS}

In summary, we proposed a simple and green approach to construct in situ micron/nano-porous and wrinkle structures on ligaments of commercial NF based on an oxidation-reduction strategy. The formation of micron/nanoporous structure was attributed to the volume expansion and shrink of Ni metal, as well as the diffusion and reconstruction of atoms during the oxidation-reduction process. The resulting MPNF was applied to support and fabricate an efficient OER electrode of MPNF- $\mathrm{MnO}_{2}$. The micron/nano-porous structures located on the ligaments of NF expand the contact area between the active material $\left(\mathrm{MnO}_{2}\right)$ and the $\mathrm{Ni}$ support, leading to enhanced OER activity and stability. The overpotential of the MPNF- $\mathrm{MnO}_{2}$ electrode at $10 \mathrm{~mA} \mathrm{~cm}{ }^{-2}$ is $363.5 \mathrm{mV}$, which is much higher than that of the $\mathrm{NF}-\mathrm{MnO}_{2}$ electrode $(429.9 \mathrm{mV})$. Furthermore, the strategy of oxidation-reduction developed in this study may open up a new and facile route to fabricate and design hierarchical porous structures on other metal systems (such as $\mathrm{Co}$., $\mathrm{Cu}$, and $\mathrm{Fe}$ ) for a wide range of structural and functional applications.

\section{DATA AVAILABILITY STATEMENT}

The original contributions presented in the study are included in the article/Supplementary Material, and further inquiries can be directed to the corresponding authors.

\section{AUTHOR CONTRIBUTIONS}

All authors listed have made a substantial, direct, and intellectual contribution to the work and approved it for publication.

\section{FUNDING}

This work was supported by Heilongjiang Natural Science Foundation (QC2018060).

Devadoss, V., Noel, M., Jayaraman, K., and Basha, C. A. (2003). Electrochemical Behaviour of $\mathrm{Mn}^{3+} / \mathrm{Mn}^{2+}, \mathrm{Co}^{3+} / \mathrm{Co}^{2+}$ and $\mathrm{Ce}^{4+} / \mathrm{Ce}^{4+}$ Redox Mediators in Methanesulfonic Acid. J. Appl. Electrochemistry 33 (3-4), 319-323. doi:10.1023/A:1024136500644

Faes, A., Hessler-Wyser, A., Zryd, A., and Van herle, J. (2012). A Review of RedOx Cycling of Solid Oxide Fuel Cells Anode. Membranes 2 (2), 585-664. doi:10.3390/membranes2030585 
Galinski, H., Bieberle-Hütter, A., Rupp, J. L. M., and Gauckler, L. J. (2011). Nonlinear Oxidation Kinetics of Nickel Cermets. Acta Materialia 59 (16), 6239-6245. doi:10.1016/j.actamat.2011.06.032

Haugsrud, R. (2003). On the High-Temperature Oxidation of Nickel. Corrosion Sci. 45 (1), 211-235. doi:10.1016/S0010-938X(02)00085-9

Huang, M., Li, F., Dong, F., Zhang, Y. X., and Zhang, L. L. (2015). $\mathrm{MnO}_{2}$-based Nanostructures for High-Performance Supercapacitors. J. Mater. Chem. A. 3 (43), 21380-21423. doi:10.1039/C5TA05523G

Julien, C., Massot, M., Rangan, S., Lemal, M., and Guyomard, D. (2002). Study of Structural Defects in ?- $\mathrm{MnO}_{2}$ by Raman Spectroscopy. J. Raman Spectrosc. 33 (4), 223-228. doi:10.1002/jrs.838

Jung, S., McCrory, C. C. L., Ferrer, I. M., Peters, J. C., and Jaramillo, T. F. (2016). Benchmarking Nanoparticulate Metal Oxide Electrocatalysts for the Alkaline Water Oxidation Reaction. J. Mater. Chem. A. 4 (8), 3068-3076. doi:10.1039/ c5ta07586f

Kim, J., Kim, J. S., Baik, H., Kang, K., and Lee, K. (2016). Porous $\beta-\mathrm{MnO}_{2}$ Nanoplates Derived from $\mathrm{MnCO} 3$ Nanoplates as Highly Efficient Electrocatalysts toward Oxygen Evolution Reaction. RSC Adv. 6 (32), 26535-26539. doi:10.1039/ c6ra01091a

Lang, X., Hirata, A., Fujita, T., and Chen, M. (2011). Nanoporous Metal/oxide Hybrid Electrodes for Electrochemical Supercapacitors. Nat. Nanotech 6 (4), 232-236. doi:10.1038/nnano.2011.13

Ledendecker, M., Clavel, G., Antonietti, M., and Shalom, M. (2015). Highly Porous Materials as Tunable Electrocatalysts for the Hydrogen and Oxygen Evolution Reaction. Adv. Funct. Mater. 25 (3), 393-399. doi:10.1002/adfm.201402078

Li, Y.-Q., Shi, X.-M., Lang, X.-Y., Wen, Z., Li, J.-C., and Jiang, Q. (2016). Remarkable Improvements in Volumetric Energy and Power of $3 \mathrm{D} \mathrm{MnO}_{2}$ Microsuper capacitors by Tuning Crystallographic Structures. Adv. Funct. Mater. 26 (11), 1830-1839. doi:10.1002/adfm.201504886

Meng, F., and Ding, Y. (2011). Sub-Micrometer-Thick All-Solid-State Supercapacitors with High Power and Energy Densities. Adv. Mater. 23 (35), 4098-4102. doi:10.1002/adma.201101678

Meng, Y., Song, W., Huang, H., Ren, Z., Chen, S.-Y., and Suib, S. L. (2014). Structure-Property Relationship of Bifunctional $\mathrm{MnO}_{2}$ Nanostructures: Highly Efficient, Ultra-stable Electrochemical Water Oxidation and Oxygen Reduction Reaction Catalysts Identified in Alkaline Media. J. Am. Chem. Soc. 136 (32), 11452-11464. doi:10.1021/ja505186m

Meulenberg, W. A., Teller, O., Flesch, U., Buchkremer, H. P., and Stöver, D. (2001). Improved Contacting by the Use of Silver in Solid Oxide Fuel Cells up to an Operating Temperature of $800^{\circ}$ C. J. Mater. Sci. 36 (13), 3189-3195. doi:10.1023/A:1017930201907

Nakamura, R., Lee, J.-G., Mori, H., and Nakajima, H. (2008). Oxidation Behaviour of Ni Nanoparticles and Formation Process of Hollow NiO. Phil. Mag. 88 (2), 257-264. doi:10.1080/14786430701819203

Thenuwara, A. C., Cerkez, E. B., Shumlas, S. L., Attanayake, N. H., McKendry, I. G., Frazer, L., et al. (2016a). Nickel Confined in the Interlayer Region of Birnessite: an Active Electrocatalyst for Water Oxidation. Angew. Chem. Int. Ed. 55 (35), 10381-10385. doi:10.1002/anie.201601935

Thenuwara, A. C., Shumlas, S. L., Attanayake, N. H., Aulin, Y. V., McKendry, I. G., Qiao, Q., et al. (2016b). Intercalation of Cobalt into the Interlayer of Birnessite Improves Oxygen Evolution Catalysis. ACS Catal. 6 (11), 7739-7743. doi:10.1021/acscatal.6b01980

Tian, L., Zhai, X., Wang, X., Pang, X., Li, J., and Li, Z. (2020). Morphology and Phase Transformation of $\alpha-\mathrm{MnO}_{2} / \mathrm{MnOOH}$ Modulated by N-CDs for Efficient Electrocatalytic Oxygen Evolution Reaction in Alkaline Medium. Electrochimica Acta 337, 135823. doi:10.1016/j.electacta.2020.135823
Tong, Y.-L., Xing, L., Dai, M.-Z., and Wu, X. (2019). Hybrid Co3O4@Co9S8 Electrocatalysts for Oxygen Evolution Reaction. Front. Mater. 6, 233. doi:10.3389/fmats.2019.00233

Wang, Z., Yan, Y., Chen, Y., Han, W., Liu, M., Zhang, Y., et al. (2017). 3DHierarchical Porous Nickel Sculptured by a Simple Redox Process and its Application in High-Performance Supercapacitors. J. Mater. Chem. A. 5 (39), 20709-20719. doi:10.1039/C7TA04293K

Xu, G.-r., Wen, Y., Min, X.-p., Dong, W.-h., Tang, A.-p., and Song, H.-s. (2015). Construction of $\mathrm{MnO}_{2} / 3$-Dimensional Porous Crack Ni for High-Performance Supercapacitors. Electrochimica Acta 186, 133-141. doi:10.1016/ j.electacta.2015.10.136

Ye, Z., Li, T., Ma, G., Dong, Y., and Zhou, X. (2017). Metal-Ion (Fe, V, Co, and Ni)Doped $\mathrm{MnO}_{2}$ Ultrathin Nanosheets Supported on Carbon Fiber Paper for the Oxygen Evolution Reaction. Adv. Funct. Mater. 27 (44), 1704083. doi:10.1002/ adfm.201704083

Yu, M., Wang, W., Li, C., Zhai, T., Lu, X., and Tong, Y. (2014). Scalable Self-Growth of Ni@NiO Core-Shell Electrode with Ultrahigh Capacitance and Super-long Cyclic Stability for Supercapacitors. NPG Asia Mater. 6 (9), e129. doi:10.1038/ am.2014.78

Yu, X.-Y., Feng, Y., Guan, B., Lou, X. W., and Paik, U. (2016). Carbon Coated Porous Nickel Phosphides Nanoplates for Highly Efficient Oxygen Evolution Reaction. Energ. Environ. Sci. 9 (4), 1246-1250. doi:10.1039/c6ee00100a

Yuan, C., Li, J., Hou, L., Zhang, X., Shen, L., and Lou, X. W. D. (2012). Ultrathin Mesoporous NiCo2O4Nanosheets Supported on Ni Foam as Advanced Electrodes for Supercapacitors. Adv. Funct. Mater. 22 (21), 4592-4597. doi:10.1002/adfm.201200994

Zeng, J., Zhang, S., Xue, J., Dai, H., Xia, L., Cai, W., et al. (2020). Enhanced Dielectric Loss and Magnetic Loss Properties of Copper Oxide-NanowireCovered Carbon Fiber Composites by Porous Nickel Film. Front. Mater. 7, 123. doi:10.3389/fmats.2020.00123

Zhao, Y., Chang, C., Teng, F., Zhao, Y., Chen, G., Shi, R., et al. (2017). DefectEngineered Ultrathin $\delta-\mathrm{MnO}_{2}$ Nanosheet Arrays as Bifunctional Electrodes for Efficient Overall Water Splitting. Adv. Energ. Mater. 7 (18), 1700005. doi:10.1002/aenm.201700005

Zhou, W., Wu, X.-J., Cao, X., Huang, X., Tan, C., Tian, J., et al. (2013). Ni3S2 nanorods/Ni Foam Composite Electrode with Low Overpotential for Electrocatalytic Oxygen Evolution. Energ. Environ. Sci. 6 (10), 2921-2924. doi:10.1039/c3ee41572d

Conflict of Interest: The authors declare that the research was conducted in the absence of any commercial or financial relationships that could be construed as a potential conflict of interest.

Publisher's Note: All claims expressed in this article are solely those of the authors and do not necessarily represent those of their affiliated organizations, or those of the publisher, the editors and the reviewers. Any product that may be evaluated in this article, or claim that may be made by its manufacturer, is not guaranteed or endorsed by the publisher.

Copyright (C) 2021 Ao, Zhao, Peng, Wang, Guo, Chen and Wang. This is an openaccess article distributed under the terms of the Creative Commons Attribution License (CC BY). The use, distribution or reproduction in other forums is permitted, provided the original author(s) and the copyright owner(s) are credited and that the original publication in this journal is cited, in accordance with accepted academic practice. No use, distribution or reproduction is permitted which does not comply with these terms. 